\title{
ChemComm
}

Check for updates

Cite this: Chem. Commun., 2020, 56, 12049

Received 7th July 2020,

Accepted 2nd September 2020

DOI: $10.1039 / \mathrm{d} 0 \mathrm{cc} 04698 \mathrm{a}$

rsc.li/chemcomm

Iterative coupling of 2-aminoisobutyric acid (Aib) has been achieved rapidly and efficiently using automated solid-phase peptide synthesis, employing diisopropylcarbodiimide (DIC) in the presence of ethyl cyanohydroxyiminoacetate (Oxyma). This method has allowed the first total synthesis of the fungal antibiotic Cephaibol D, and enabled the synthesis of water-soluble oligomers of Aib containing up to an unprecedented sequence of 17 consecutive Aib residues. Conformational analysis of the Aib oligomers in aqueous solution shows a length dependence in their CD spectra, with oligomers of more than 14 Aib residues apparently adopting structured helical conformations.

De novo protein design using both rational and computational approaches allows a wide range a novel peptide structures to be explored. ${ }^{1,2} \alpha$-Helices have been widely used as design components of these novel proteins. ${ }^{3,4}$ However, the $3_{10}$ helix, an analogue of the $\alpha$-helix with only three residues per turn and also found in natural protein structures, has gained significantly less attention. ${ }^{5}$ A general strategy for incorporating long $3_{10}$-helical modules into artificial proteins would advance de novo protein design, allowing use of a new secondary structure in synthetic proteins.

The extended $3_{10}$-helical conformation is commonly adopted by peptides with a high density of $\alpha, \alpha$-disubstituted amino acids, ${ }^{6}$ the simplest of which is aminoisobutyric acid (Aib, abbreviated here as U). ${ }^{7}$ However, these $3_{10}$ helices tend to collapse towards $\alpha$-helical conformations in more polar solvents, ${ }^{8}$ and while the conformational properties of Aib oligomers have been studied in organic solvents ${ }^{9,10}$ and membranes,${ }^{11}$ it is not clear whether

\footnotetext{
${ }^{a}$ School of Chemistry, University of Bristol, Cantock's Close, Bristol, BS8 1TS, UK. E-mail:D.N.Woolfson@bristol.ac.uk, j.clayden@bristol.ac.uk

${ }^{b}$ School of Biochemistry, University of Bristol, Medical Sciences Building, University Walk, Bristol, BS8 1TS, UK

${ }^{c}$ Bristol BioDesign Institute, University of Bristol, Life Sciences Building, Tyndall Avenue, Bristol BS8 1TQ, UK

$\dagger$ Electronic supplementary information (ESI) available: Peptide synthesis, peptide purification, circular dichroism spectroscopy and analytical data. See DOI: $10.1039 /$ d0cc04698a
}

long Aib-rich structures can be maintained in water. Indeed, there are few reported examples of water-soluble $3_{10}$ helices. The gp41 $1_{659-671}$ peptide adopts a $3_{10}$ helix in water, and, remarkably, it is made up entirely of proteinogenic amino acids. ${ }^{12}$ Toniolo and co-workers report a water-soluble Aib-rich $3_{10}$ helix with (L)-2-amino-3[1-(1,4,7-triazacyclononane)]propanoic acid residues placed three residues apart to allow aqueous solvation, ${ }^{13}$ but this peptide is only 7 residues in length.

Here, we show that it is possible to form long oligomers of Aib (up to 17 consecutive residues) that are soluble in water. To achieve this, we developed conditions that allow iterative successive coupling of hindered $\alpha, \alpha$-disubstituted amino acids on a solid-phase support. For the first time, this allows the synthesis of long Aib-rich sequences by automated solid-phase peptide synthesis (SPPS).

The conformational properties of Aib oligomers-typically of 4-12 monomers-have been studied in non-aqueous solvents by making use of an iterative solution-phase acylationreduction sequence. ${ }^{9}$ However, the standard technique for the synthesis of natural and unnatural peptide sequences is SPPS, ${ }^{14}$ employing the base-labile Fmoc group to protect the $\alpha$-amino group of the growing peptide chain, and orthogonal acid-labile peptide-resin linkages and side-chain protecting groups. ${ }^{15}$ Automation of SPPS $^{16}$ has accelerated coupling-deprotection cycles to the extent that each single-residue chain extension may take as little as four minutes in microwave-equipped instruments. ${ }^{17}$ Although these standard conditions work well with proteinogenic and other $\alpha$-amino acids, they give poor yields with sterically hindered $\alpha, \alpha$-disubstituted amino acids such as Aib.

Nonetheless, successive Aib residues may be coupled to a peptide chain using SPPS much more rapidly than in solution. ${ }^{7}$ Hara and co-workers report the use of 3-nitro-1,2,4-triazol-1yltris(pyrrolidin-1-yl)phosphonium hexafluorophosphate (PyNTP) to couple up to 10 successive Aib residues in high yield with a coupling time of only 20 minutes at room temperature. ${ }^{18}$ The drawback of this approach is that 20 equivalents of PyNTP and of base are required. Also, the expense and instability of 
phosphonium and uronium salts makes them less attractive for routine use in automated synthesis.

A more-appealing approach to Aib couplings employs ethyl cyanohydroxyiminoacetate (Oxyma). Initially reported in the 1970 s as a way to reduce epimerisation, ${ }^{19}$ this weakly acidic oxime has been applied in conjunction with DIC to enable difficult couplings on a solid support by Albericio and coworkers. ${ }^{20}$ Oxyma allows two consecutive Aib residues to be coupled using DIC more efficiently than with common HOAt and HOBt additives. Oxyma is also stable in DMF and does not cap the resin prematurely during synthesis; two factors that favour its utility in automated SPPS. A variety of oxonium and phosphonium coupling reagents based on Oxyma have been reported, such as COMU and PyOxim. ${ }^{21}$

The combination of DIC with Oxyma has found use in microwave-assisted automated SPPS, ${ }^{17}$ and Oxyma's superiority as an activating additive has been demonstrated for coupling two successive Aib residues during the synthesis of the peptaibols alamethicin and bergofungin. ${ }^{22}$ Using two equivalents of DIC relative to the amino acid (or 10 equivalents relative to the resin loading) significantly increases peptide purity, ${ }^{23}$ by increasing the rate of formation of O-acylurea, accelerating the activation of the amino acid. The use of DIC + Oxyma is generally considered the method of choice for difficult peptide couplings using microwave assisted automated SPPS. ${ }^{24}$

Using DIC + Oxyma as the coupling method, we explored the types of water-soluble Aib-rich sequences that could be made by automated SPPS. To validate the method for making Aib-rich structures, we targeted Cephaibol D (1, Fig. 1), ${ }^{25}$ a 15-residue peptaibol containing eight Aib (U) and two hydroxyproline (O) residues. A partial synthesis of this molecule has been reported $^{26}$ but not a total synthesis. The Aib residues occur as a synthetically challenging group of four consecutive residues, a pair of consecutive Aib residues followed by hydroxyproline (UUO), and a UOUP motif towards the $\mathrm{C}$ terminus.

Starting from preloaded Fmoc-phenylalaninol $o$-chlorotrityl resin $\left(0.44 \mathrm{mmol} \mathrm{g}^{-1}\right)$ and using Fmoc protection of the $\mathrm{N}$ terminus, 1 was synthesised on a $0.1 \mathrm{mmol}$ scale using 5 equivalents of amino acid and Oxyma and 10 equivalents of

A

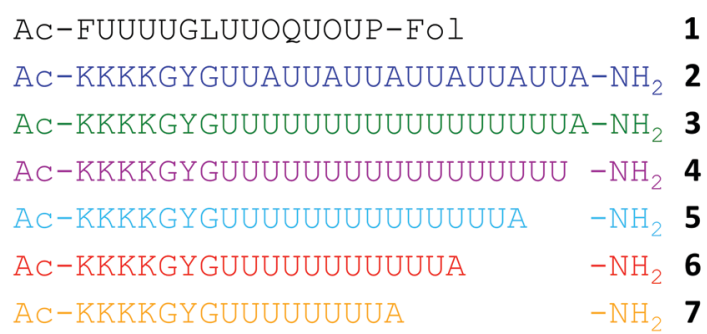

B

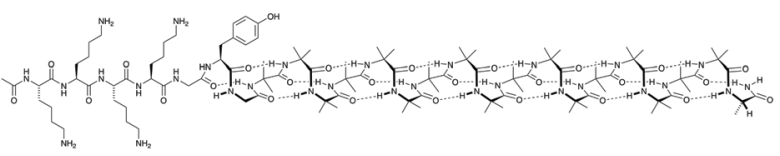

Fig. 1 (a) Sequences of Cephaibol D 1 and other peptides synthesised (2-7). (b) Displayed structure of 3. Key: U, Aib; O, Hyp; Fol, phenylalaninol.
Table 1 Analysis and purity of synthesised peptides

\begin{tabular}{llll}
\hline Product & $\begin{array}{l}\text { Synthesis time } \\
(\mathrm{h}: \text { min) }\end{array}$ & $\begin{array}{l}\text { Crude } \\
\text { purity }(\%)\end{array}$ & $\begin{array}{l}\text { Isolated } \\
\text { yield (\%) }\end{array}$ \\
\hline $\mathbf{1}$ & $5: 37$ & 40 & 26 \\
$\mathbf{2}$ & $8: 22$ & 67 & 41 \\
$\mathbf{3}$ & $8: 19$ & 59 & 21 \\
$\mathbf{4}$ & $8: 03$ & 61 & 19 \\
$\mathbf{5}$ & $7: 01$ & 61 & 33 \\
$\mathbf{6}$ & $6: 19$ & 75 & 52 \\
7 & $5: 10$ & 74 & 55
\end{tabular}

DIC in each coupling cycle. The optimum conditions for coupling were irradiation at $90{ }^{\circ} \mathrm{C}$ for $3 \mathrm{~min}$ with standard amino acids, or at $100{ }^{\circ} \mathrm{C}$ for 10 min with Pro, Hyp, Aib and any amino acid required to couple to an N-terminal Aib. Each Fmoc deprotection was achieved using a $20 \%$ solution of morpholine in DMF with formation of the morpholinefulvene adduct monitored by UV absorption at $301 \mathrm{~nm}$ to estimate coupling efficacy (see ESI $\dagger$ ). On completion of the synthesis, the $\mathrm{N}$ terminus of the peptide was acetylated on the resin with a solution of acetic anhydride and DIPEA in DMF for $30 \mathrm{~min}$. The peptide was cleaved from the resin and deprotected in dilute TFA to prevent cleavage of Aib-Pro bond. ${ }^{22}$

This approach gave Cephaibol D 1 in just over $5.5 \mathrm{~h}$ with high crude purity (Table 1), as determined by HPLC (Fig. 2). Purification by semipreparative HPLC gave 1 in $26 \%$ yield over 15 coupling and deprotection steps.

This successful first total synthesis of Cephaibol D demonstrates that multiple Aib-on-Aib couplings are possible in high yield using SPPS without recourse to large excesses of phosphonium salts. On this basis, we designed longer sequences containing consecutive Aib residues and maintaining water solubility to allow purification by reverse-phase HPLC. The extended Aib-rich sequences 2 and $\mathbf{3}$ are similar to the Aib-rich $3_{10}$ helices studied in organic solvents. ${ }^{9,26}$ However, to facilitate solubility in water, they incorporate a 7-residue cationic tag, KKKKGYG. The tag was positioned at the $\mathrm{N}$ terminus of the

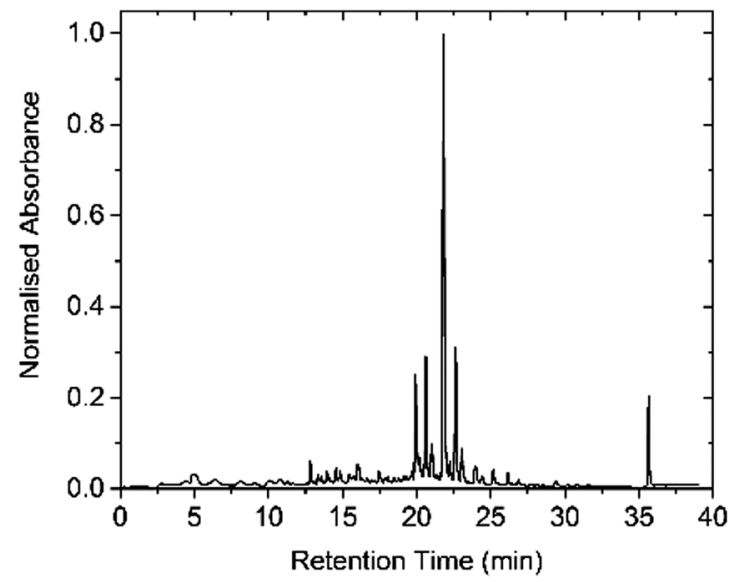

Fig. 2 HPLC profile of crude Cephaibol D 1 (detection at $220 \mathrm{~nm}$ ). The peak at 22 min was identified as Cephaibol D by MALDI-TOF mass spectrometry. 

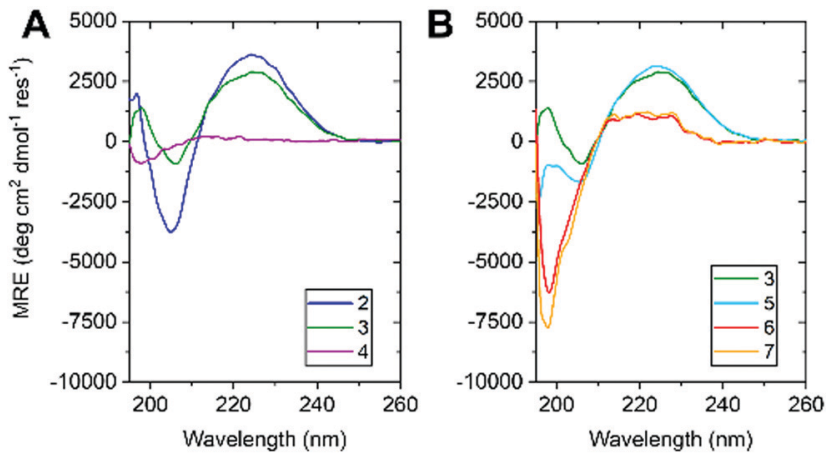

Fig. 3 CD spectra of (A) 2, 3 \& 4 and (B) 3, 5, 6 \& 7 in $\mathrm{H}_{2} \mathrm{O}(100 \mu \mathrm{M}, 1 \mathrm{~mm}$ pathlength, $5{ }^{\circ} \mathrm{C}, \mathrm{PBS}, \mathrm{pH}$ 7.4). Colour coded as in Fig. 1.

peptide to avoid interference with the folding of the Aib-rich segment and incorporated a glycine-flanked ${ }^{27}$ chromophore to allow the aqueous concentration to be quantified.

As Aib is achiral, its oligomers populate equally pairs of enantiomeric confomers. ${ }^{28}$ Therefore, observation of conformation by circular dichroism (CD) spectroscopy requires at least one chiral residue to induce a screw-sense preference. The 6-fold UUA repeat of 2 incorporates a high density of chiral residues to induce a screw sense preference. Nonetheless, the screw sense of an Aib oligomer can be propagated from a single chiral residue. ${ }^{29}$ Therefore, we made 3 , which is identical in length to 2 but with a single Ala residue adjacent to 17 consecutive Aib residues. Control peptide 4, lacking the Ala residue, was made to verify the conformational influence of the cationic tag. 2, 3 and 4 were synthesised using the same conditions as 1, replacing Fmoc-phenylalaninol $o$-chlorotrityl resin with rink amide MHBA resin, and using more powerfully acidic conditions for resin cleavage and side-chain deprotection (see ESI $\dagger$ ). All three peptides were synthesised in just over 8 hours with acceptable crude purities and isolated yields (Table 1 ).

The water-soluble peptides 2 and 3 allowed the first ever observation of the CD spectrum of Aib oligopeptides in aqueous solution (100 $\mu \mathrm{M}$, PBS buffer). CD spectra of 2 and 3 (Fig. 3a) resembled spectra of Aib oligomers in organic solvents, ${ }^{9}$ with a negative signal at $205 \mathrm{~nm}$ (indicating a right-handed screw sense preference) and a positive maximum at $225 \mathrm{~nm} .{ }^{30}$ The moreintense CD signal of 2 can be attributed to the greater density of Ala residues, giving 2 a greater average screw-sense preference than 3. Nonetheless, the comparable magnitude of their CD signals suggests that a substantial proportion of 3 adopts a righthanded screw sense, induced from the $\mathrm{C}$ terminus (Fig. 1b). ${ }^{9 d}$ Peptide 4 had no signal in the range $210-260 \mathrm{~nm}$, confirming that the cationic tag does not induce a screw-sense preference.

Previous data recorded in organic solvents suggest that the stability of the helical conformation adopted by oligomers rich in $\alpha, \alpha$-disubstituted amino acids is length dependent. ${ }^{31,32}$ Therefore, we synthesised 5, $6 \& 7$, shorter homologues of 3 with 14, 11 and 8 consecutive Aib residues, respectively. 6 and 7 showed no evidence of folding, despite their C-terminal L-Ala residue (Fig. 3b), suggesting that oligomers of fewer than 11 Aib residues do not form stable helices in water.
Peptide 5, with 14 Aib residues, behaved quite differently to the others. Immediately after dissolving in PBS buffer, its CD spectrum matched closely that of 3 , suggesting that a 14-mer of Aib may adopt a structured conformation in water. However, over a period of minutes at room temperature, the CD curve changed to one characteristic of a random coil (Fig. S1, ESI $\dagger$ ). Further exploration of the details of the structure adopted by amphipathic peptides 2, 3 and 5, and of the conformational transition of $\mathbf{5}$ in water, is under way.

In summary, long chains of Aib residues can be synthesised rapidly and in high yield by automated SPPS using DIC with an Oxyma coupling cocktail. This method has allowed the first total synthesis of Cephaibol D. The coupling of 17 consecutive Aib residues has been achieved in only 8 hours, which is much more rapid than alternative methods. Capping the Aib oligomers with a cationic tag makes them water-soluble, and these water-soluble Aib oligopeptides show CD spectra similar to those seen in organic solvents. We anticipate that this work will be of value in the de novo design, synthesis and characterisation of both water-soluble and membrane-active helical peptides built from non-proteinogenic residues.

F. Z. thanks Dr Caroline Morris for helpful discussions and assistance with the peptide synthesiser. This work was supported by the EPSRC funded Bristol Chemical Synthesis Centre for Doctoral Training EP/G036764/1 (studentship to F. Z.) and programme grant EP/P027067 (awarded to JPC). DNW held a Royal Society Wolfson Research Merit Award (WM140008). We also thank the University of Bristol School of Chemistry Mass Spectrometry Facility for use of the EPSRC-funded Bruker Ultraflex MALDI-TOF/TOF instrument (EP/K03927X/1), and the BBSRC/EPSRC-funded BrisSynBio (BB/L01386X1) for access to its peptide synthesisers.

\section{Conflicts of interest}

There are no conflicts to declare.

\section{Notes and references}

1 L. Regan, D. Caballero, M. R. Hinrichsen, A. Virrueta, D. M. Williams and C. S. O'Hern, Biopolymers, 2015, 104, 332.

2 P. S. Huang, S. E. Boyken and D. Baker, Nature, 2016, 537, 320.

3 D. N. Woolfson, in Fibrous Proteins: Structures and Mechanisms, ed. D. A. D. Perry and J. M Squire, Springer, Cham, 1st edn, 2017, vol. 82 , ch. 2, pp. 35-62.

4 I. V. Korendovych and W. F. DeGrado, Q. Rev. Biophys., 2020, 53, 1.

5 L. Pal and G. Basu, Protein Eng., 1999, 12, 811.

6 R. Hummel, C. Toniolo and G. Jung, Angew. Chem., Int. Ed. Engl., 1987, 26, 1150.

7 J. Clayden, A. Castellanos, J. Solà and G. A. Morris, Angew. Chem., Int. Ed., 2009, 48, 5962.

8 (a) T. S. Yokum, T. J. Gauthier, R. P. Hammer and M. L. McLaughlin, J. Am. Chem. Soc., 1997, 119, 1167; (b) P. Pengo, L. Pasquato, S. Moro, A. Brigo, F. Fogolari, Q. B. Broxterman, B. Kaptein and P. Scrimin, Angew. Chem., Int. Ed., 2003, 42, 3388.

9 (a) R. A. Brown, T. Marcelli, M. De Poli, J. Solà and J. Clayden, Angew. Chem., Int. Ed., 2012, 51, 1395; (b) M. De Poli, L. Byrne, R. A. Brown, J. Solà, A. Castellanos, T. Boddaert, R. Wechsel, J. D. Beadle and J. Clayden, J. Org. Chem., 2014, 79, 4659; (c) B. A. F. Le Bailly and J. Clayden, Chem. Commun., 2014, 50, 7949; (d) M. Tomsett, I. Maffucci, B. A. F. Le Bailly, L. Byrne, S. M. Bijvoets, M. G. Lizio, 
J. Raftery, C. P. Butts, S. J. Webb, A. Contini and J. Clayden, Chem. Sci., 2017, 8, 3007.

10 (a) R. A. G. D. Silva, S. C. Yasui, J. Kubelka, F. Formaggio, M. Crisma, C. Toniolo and T. A. Keiderling, Biopolymers, 2002, 65, 229; (b) A. Moretto, M. Crisma, F. Formaggio, B. Kaptein, Q. B. Broxterman, T. A. Keiderling and C. Toniolo, Pept. Sci., 2007, 88, 233.

11 (a) S. J. Pike, J. E. Jones, J. Raftery, J. Clayden and S. J. Webb, Org. Biomol. Chem., 2015, 13, 9580; (b) J. E. Jones, V. Diemer, V. C. Adam, J. Raftery, R. E. Ruscoe, J. T. Sengel, M. I. Wallace, A. Bader, A. S. L. Cockroft, J. Clayden and S. J. Webb, J. Am. Chem. Soc., 2016, 138, 688; (c) C. Adam, A. D. Peters, M. G. Lizio, G. F. S. Whitehead, V. Diemer, J. A. Cooper, S. L. Cockroft, J. Clayden and S. J. Webb, Chem. - Eur. J., 2018, 24, 2249.

12 Z. Biron, S. Khare, A. O. Samson, Y. Hayek, F. Naider and J. Agister, Biochemistry, 2002, 41, 12687.

13 F. Formaggio, M. Crisma, P. Rossi, P. Scrimin, B. Kaptein, Q. B. Broxterman, J. Kamphuis and C. Toniolo, Chem. - Eur. J., 2000, 6, 4498.

14 R. B. Merrifield, J. Am. Chem. Soc., 1963, 85, 2149.

15 L. Carpino and G. Han, J. Org. Chem., 1972, 37, 3404.

16 (a) J. M. Collins and N. E. Leadbeater, Org. Biomol. Chem., 2007, 5, 1141; (b) J. Murray, J. Aral and L. Miranda, Methods Mol. Biol., 2011, 716, 73; (c) S. L. Pedersen, A. P. Tofteng, L. Malik and K. J. Kensen, Chem. Soc. Rev., 2012, 41, 1826.

17 J. M. Collins, K. A. Porter, S. K. Singh and G. S. Vanier, Org. Lett., 2014, 16, 940.

18 R. I. Hara, Y. Mitsuhasi, K. Saito, Y. Maeda and T. Wada, ACS Comb. Sci., 2018, 20, 13 .
19 (a) M. Itoh, Bull. Chem. Soc. Jpn., 1973, 46, 2219; (b) J. Izdebski, Pol. J. Chem., 1979, 53, 1049.

20 R. Subirós-Funosas, R. Prohens, R. Barbas, A. El-Faham and F. Albericio, Chem. - Eur. J., 2009, 15, 9394.

21 (a) A. Kumar, Y. E. Jad, B. G. de la Torre, A. El-Faham and F. Albericio, J. Pept. Sci., 2017, 23, 763; (b) A. El-Faham and F. Albericio, Chem. Rev., 2011, 111, 6557.

22 K. B. H. Salah and N. Inguimbert, Org. Lett., 2014, 16, 1783.

23 J. M. Collins and S. K. Singh, US Pat., 0066031 A1, 2018.

24 A. El-Faham and F. Albericio, Org. Process Res. Dev., 2018, 22, 760.

25 M. Schiell, J. Hofmann, M. Kurz, F. R. Schmidt, L. Vértesy, M. Vogel, J. Wink and G. Seibert, J. Antibiot., 2001, 54, 220.

26 U. Orcel, M. De Poli, M. De Zotti and J. Clayden, Chem. - Eur. J., 2013, 19, 16357.

27 T. Boddaert, J. Solà, M. Helliwell and J. Clayden, Chem. Commun., 2012, 48, 3397.

28 J. Solà, G. A. Morris and J. Clayden, J. Am. Chem. Soc., 2011, 133, 3712.

29 B. A. F. Le Bailly, L. Byrne, V. Diemer, M. Foroozandeh, G. A. Morris and J. Clayden, Chem. Sci., 2015, 6, 2313.

30 Toniolo and coworkers report that the sign of the signal at $222 \mathrm{~nm}$ in Aib-containing helices is slightly negative, rather than positive. The origin of this consistent discrepancy is still unclear. See E. Longo, A. Moretto, F. Formaggio and C. Toniolo, Chirality, 2011, 23, 756-760.

31 I. L. Karle, J. L. Flippen-Anderson, R. Gurunath and P. Balaram, Protein Sci., 1994, 3, 1547.

32 (a) S. C. Yasui, T. A. Kiederling, F. Formaggio, G. M. Bnora and C. Toniolo, J. Am. Chem. Soc., 1986, 108, 4988; (b) K. Otoda, Y. Kitagawa, S. Kimura and Y. Imanishi, Biopolymers, 1993, 33, 1337. 